\title{
SISTEM PAKAR DIAGNOSA KERUSAKAN SEPEDA MOTOR MATIC INJEKSI MENGGUNAKAN METODE FORWARD CHAINING BERBASIS ANDROID
}

\author{
Anggri Sartika Wiguna ${ }^{1}$, Isman Harianto ${ }^{2}$ \\ ${ }^{1,2}$ Teknik Informatika, Universitas Kanjuruhan Malang \\ 1,2 anggrisartikawiguna@unikama.ac.id, ismanharianto87@gmail.com
}

\begin{abstract}
Abstrak- Perkembangan industri sepeda motor matic injeksi di indonesia mengalami perkembangan yang signifikan, sepeda motor matic injeksi yang lebih irit bahan bakar dan ramah lingkungan, dengan tingginya pengguna sepeda motor matic injeksi saat ini timbul permasalahan bahwa tidak semua pengguna motor matic injeksi memiliki kemampuan melakukan perbaikan terhadap kerusakan sepeda motornya. Dengan kemajuan teknologi smarthphone saat ini, memunculkan suatu ide atau gagasan aplikasi sistem pakar ke dalam aktivitas mutu pelayanan smartphone. Sistem yang akan dibuat adalah "Sistem pakar diagnosa kerusakan sepeda motor matic injeksi menggunakan metode forward chaining berbasis mobile" aplikasi ini akan menggunakan metode forward chaining. Sistem pakar ini diharapkan dapat membantu pengguna mengetahui kerusakan dan melakukan perbaikan sepeda motornya lebih awal sebelum terjadi kerusakan yang berkelanjutan. Sistem ini dibangun menggunakan aplikasi Basic4android.
\end{abstract}

Kata kunci : Motor matic injeksi, Sistem pakar, Forward chaining.

\section{PENDAHULUAN}

Sistem pakar di kembangkan sejalan dengan adanya teknologi informasi, pembangunan sistem pakar bertujuan sebagai sarana bantu untuk memberikan solusi dalam kehidupan kita, salah satu khasus contohnya kerusakan sepeda motor matic injeksi, perkembangan industri sepeda motor matic di indonesia mengalami perkembangan yang signifikan. Motor matic saat ini merupakan jenis kendaraan yang paling di minati banyak pengendara karena mudah untuk di kendarai, ekonomis dan nyaman. Terutama motor matic injeksi yang lebih irit bahan bakar, motor matic seakan menjadi kendaraan favorit masyarakat saat ini serta menjadi kendaraan yang paling di nikmati oleh banyak kalangan. Sehingga di butuhkan perawatan yang intensif pada motor matic injeksi, dengan perawatan yang intensif akan membuat motor matic injeksi lebih nyaman saat dikendarai.

Mengingattingginya pengguna sepeda motor matic injeksi saat ini timbul permasalahan bahwa tidak semua pengguna motor matic injeksi memiliki kemampuan melakukan perbaikan terhadap kerusakan sepeda motornya. Pengguna lebih mempercayakan masalah itu pada mekanik bengkel, akan tetapi jam kerjanya terbatas. Dengan semua aktivitas yang padat dan penuh khususnya di kota kota besar, telah menuntut masyarakat untuk mengerjakan segala sesuatunya dengan cepat dan tepat. Waktu telah menjadi modal utama yang sangat berharga. Perawatan yang kiranya bisa dilakukan sendiri, serta tanpa harus datang ke bengkel dengan membawa kendaraan tersebut, akan sangat membantu sekali, khususnya untuk orang - orang yang awam tentang. otomotif dan tidak mempunyai waktuuntuk datang ke bengkel menunggu sampai kendaraannya selesai direparasi.

Pembuatan sistem pakar pernah diteliti oleh Dian kusuma wati dan Wiwin kuswinardi dalam penelitian yang berjudul Sistem pakar diagnosa kerusakan sepeda motor matic injeksi menggunakan metode dempster shafer. Hasil pembuatan sistem pakar yang berbasis delphi tersebut menunjukkan bahwa sistem pakar yang telah dibuat dapat mendiagnosa kerusakan motor matic injeksi berdasarkan gejala yang dialami.

Berdasarkan uraian diatas, peneliti tertarik untuk melakukan penelitian yang berjudul Sistem pakar diagnosa kerusakan sepeda motor matic injeksi menggunakan metode forward chaining berbasis android. Penelitian ini sedikit berbeda dengan penelitian yang dilakukan oleh Dian kusuma wati dan Wiwin kuswinardi yang hanya menampilkan jenis kerusakan dan solusinya, penelitian ini akan dilengkapi dengan cara perawatan motor matic injeksi, Sistem pakar ini akan lebih terasa efektif serta efisien, pengguna dapat dengan mudah dan cepat mendapatkan informasi dimana pun dan kapan pun. Hal tersebut dapat dilakukan dengan menggunakan aplikasi sistem pakar berbasis android yang bersifat dinamis. 


\section{Tinjauan Pustaka}

\section{A. Sistem Pakar}

Secara umum sistem pakar (expert system) adalah system yang berusaha mengadopsi pengetahuan manusia ke komputer agar komputer dapat menyelesaikan masalah seperti biasa yang dilakukan oleh para ahli. Sistem pakar yang baik dirancang agar dapat menyelesaikan suatu permaslahan tertentu dengan meniru kerja dari para ahli. Dengan sistem pakar ini, orang awampun juga diharapkan dapat menyelesaikan masalah yang cukup rumit. Dimana yang sebenarnya hanya dapat diselesaikan dengan bantuan para ahli. Bagi para ahli, sistem pakar ini juga akan membantu aktivitasnya sebagai asisten yang sangat berpengalaman. Namun sistem pakar sulit untuk di kembangkan apa bila tidak ada seorang pakar. (Turban, 2005)

Ciri - ciri Sistem pakar sistem pakar menurut Arhami, M (2005) adalah sebagai

Berikut :

1. Terbatas pada domain keahlian tertentu.

2. Dapat memberikan penalaran untuk data yang tidak pasti.

3. Dapat mengemukakan rangkaian alasan - alasan yang diberikannya dengan cara yang dapat di pahami.

4. Berdasarkan pada kaidah atau ketentuan atau rule tertentu.

5. Dirancang dapat untuk dapat dikembangkan secara bertahap.

6. pengetahuan dan mekansme penalaran (interfance) jelas terpisah.

7. keluarnya bersifat anjuran.

8. Sistem dapat mengaktifkan kaidah secara searah yang sesuai dituntunoleh dialog dengan user.

\section{B. Android}

Android adalah sistem operasi untuk telepon seluler yang berbasis Linux. Android menyediakan platform terbuka bagi para pengembang buat menciptakan aplikasi mereka sendiri untuk digunakan oleh bermacam peranti bergerak. Awalnya, Google Inc. membeli android Inc, pendatang baru yang membuat peranti lunak untuk ponsel. Kemudian untuk mengembangkan android, dibentuklah Open Handset Alliance, konsorsium dari 34 perusahaan peranti keras, peranti lunak, dan telekomunikasi, termasuk Google, HTC, Intel, Motorola, Qualcomm, T-Mobile, dan Nvidia.

Saat ini terdapat dua jenis distributor sistem operasi Android. Pertamayang mendapat dukungan penuh dari Google atau Google Mail Services (GMS), seperti yang terdapat pada smartphone nexus keluaran google yang bekerja sama dengan vendor smartphone HTC, dan kedua adalah yang benar - benar bebas distribusinya tanpa dukungan langsung Google atau dikenal sebagai Open Handset Distribution (OHD), jenis yang kedua ini jenis - jenis yang banyak terdapat pada smartphone android di pasaran. (Ardiansyah, F. 2011)
Basic4android adalah development tool sederhana yang powerful untuk membangun aplikasi Android. Bahasa Basic4android mirip dengan Visual Basic dengan tambahan dukungan untuk objek.

Aplikasi Android (APK) yang dicompile oleh Basic4Android adalah aplikasi Android native/asli dan tidak ada extra runtime seperti di Visual Basic yang ketergantungan file msvbvm60.dll, yang pasti aplikasi yang dicompile oleh Basic4Android adalah no dependencies (tidak ketergantungan file lain). IDE Basic4Android hanya fokus pada development Android. (Uziel,2011)

Forward chaining merupakan grup dari multipel inferensi yangmelakukan pencarian dari suatu masalah kepada solusinya, Forward chaining merupakan proses perunutan yang dimulai dengan menampilkan kumpulan data atau fakta yang meyakinkan menuju konklusi akhir. (Ivon Idiego,2010)Jadi metode forward chaining dimulai dari informasi masukan (if) dahulu kemudian menuju konklusi (then) atau dapat dimodelkan sebagai berikut :

IF (informasi masukan)

THEN (konklusi)

Informasi masukan dapat berupa data, bukti, temuan atau pengamatan, sedangkan konklusi dapat berupa tujuan, penjelasan, atau diagnosa.

\section{C.Motor Matik Injeksi}

injeksi, merupakan suatu metode pencampuran bahan bakar dengan udara pada kendaraan bermotor untuk menghasilkan pembakaran yang sempurna. Injeksi membutuhkan perangkat bernama injector, yang bertugas menyuplai campuran bahan bakar dengan udara. Sistem injeksi merupakan teknologi penerus sistem karburator pada kendaraan bermotor. (Moch. Solikin, 2011).

Cara kerja motor matic injeksi apabila pada sistem karburator, kendaraan membutuhkan penyetelan yang tepat agar bisa mendapatkan campuran bahan bakar dan udara atau AFR (Air-fuel ratio) yang optimal, sistem injeksi sudah terprogram secara komputer untuk mendapatkan rasio AFR yang optimal. Supaya bisa mendapatkan AFR yang optimal, injektor mengandalkan program komputer untuk mengontrol AFR nya. Perangkat elektronik yang bertugas untuk mengontrol kerja injektor ini bernama ECM atau Electronic Control Module. (Moch. Solikin, 2011)

Adapun kelebihan motor matic injeksi adalah :

1. Pembakaran menjadi sempurna.

2. Konsumsi bbm lebih irit.

3. Tidak perlu repot melakukan penyetelan

4. Tidak perlu susah dalam melakukan servis.

Kelemahan Motor Injeksi

1.Masih sedikit bengkel umum yang menerima servis injeksi.

2. Harga yang mahal.

3. Sulit untuk modifikasi.

4. Sensitif terhadap perangkat kelistrikan. 


\section{Metode Penelitian}

\section{A. Analisis Kebutuhan Sistem}

Analisis kebutuhan sistem sangat dibutuhkan dalam mendukung kinerja sistem. Apakah sistem yang dibuat sudah sesuai dengan yang di butuhkan atau belum, karena kebutuhan sistem akan mendukung tercapainya tujuan suatu instansi atau perusahaan. Dengan adanya sistem baru yang telah dibuat diharapkan dapat lebih membantu dalam kinerja sistem dan mempermudah pengguna motor matic injeksi dalam memperoleh informasi informasi yang diperlukanuntuk mempermudah analisis sistem dalam menentukan kerusakan motor matic injeksi, maka dibagi kebutuhan sistem menjadi dua blok yaitu kebutuhan fungsional dan non fungsional.

\section{B. Perancangan Pohon Keputusan}

Diagram pohon keputusan merupakan suatu rancangan yang digunakan untuk membangun sebuah sistem pakar, di dalam diagram pohon keputusan tersebut akan dicari solusi hasil akhir dari setiap pemeriksaan. Pohon keputusan dapat dilihat pada gambar 1 berikut :

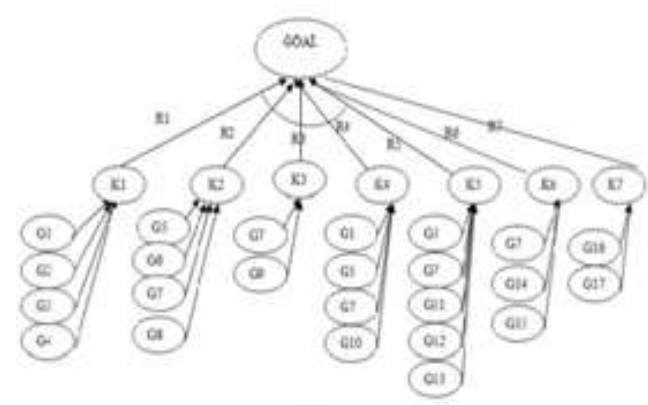

Gambar 1 Pohon Keputusan

\section{Data Gejala dan Data Kerusakan}

Data Gejala dan data kerusakan berisi tentang kerusakan dan gejala motor matic injeksi. Yang di peroleh dari seorang pakar.

\begin{tabular}{|c|c|c|c|c|c|c|c|c|}
\hline \multirow[b]{2}{*}{ No } & \multirow[b]{2}{*}{ Gejala } & \multicolumn{7}{|c|}{ Kode Kerusakan } \\
\hline & & $\mathrm{K} 1$ & $\mathrm{~K} 2$ & $\mathrm{~K} 3$ & K4 & KS & K6 & $K^{\prime} ?$ \\
\hline 1 & GI & $*$ & & & $\cdot$ & & & \\
\hline 2 & G2 & $\bullet$ & & & & & & \\
\hline 3 & $\mathrm{G}^{3}$ & $\bullet$ & & & & & & \\
\hline 4 & G4 & $\bullet$ & & & & & & \\
\hline 5 & GS & & $\cdot$ & & $\cdot$ & $*$ & & \\
\hline 6 & G6 & & $\bullet$ & & & & & \\
\hline 7 & G? & & $\bullet$ & $*$ & $\cdot$ & $*$ & $\cdot$ & \\
\hline 8 & G8 & & $\bullet$ & & & & & \\
\hline 9 & G9 & & & $*$ & & & & \\
\hline 10 & G10 & & & & $\bullet$ & & & \\
\hline 11 & G11 & & & & & * & & \\
\hline 12 & $\mathrm{G} 12$ & & & & & 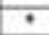 & & \\
\hline 13 & $\mathrm{GI3}$ & & & & & + & & \\
\hline 14 & G14 & & & & & & 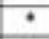 & \\
\hline 15 & G15 & & & & & & $\cdot$ & \\
\hline 16 & G16 & & & & & & & $\bullet$ \\
\hline 17 & G:7 & & & & & & & $\bullet$ \\
\hline
\end{tabular}

Tabel 1 Data Gejala dan Data Kerusakan

\section{K4 : Injector}

K5 : Roller

2. Keterangan kode kerusakan :

$\mathrm{K} 1$ : Acu

$\mathrm{K} 2$ : Busi

K3 : Celah Klep

$\mathrm{K} 4$ : Injector

K5 : Roller

K6 : CVT

$\mathrm{K} 7$ : ECM

3. Keterangan gejala yang timbul :

G1 : Di stater listrik tidakbisa

G2 : Klakson tidak bunyi

G3 : Reating dan lampu tidak bekerja

G4 : Kelistrikan mati

G5 : Di stater manual sulit

G6 : Suara knalpot sering meletus-meletus

G7 : Tarikan berat

G8 : Keluar Asap kehitaman pada knalpot

G9 : Mesin mudah panas

G10: Bahan bakar boros

G11: Bunyi gemelitik pada mesin

G12: Suara mesin kasar

G13: Kecepatan tidakoptimal

G14: Bunyi kasar saat jalan pelan

G15: Kampas kopling lambat

G16: Lari mrebet-mrebet

G17: Motor mati (tidak bisa hidup sama sekali)

\section{Data Aturan}

Baris aturan yang terdiri dari data gejala dan data kerusakan di gabungkan sesuai dengan apa keputusan yang di ambil oleh seorang pakar, serta tabel keputusan yang kemudian disusun dalam bentuk aturan dengan menggunakan metode forward chaining yang dapat di lihat pada tabel berikut :

\begin{tabular}{|c|c|}
\hline Ature (Rule) & Kritah Proutsi (AND) \\
\hline RI & IFGI AD G2ADG GADDGI THENKI \\
\hline R2 & IF G5AD G6 ADGTAD G8 THENK? \\
\hline R3 & IF G7 AD G9THENB3 \\
\hline Rt & IFGI ADD G5ANG GANDG10 THENK4 \\
\hline $\mathrm{Rj}$ & IF G5 AV GT AV G11 AND G12AND G13 THENK: \\
\hline $\mathrm{R} 6$ & If G7 AVD GIA AND G15 THEN K6 \\
\hline$R^{-1}$ & IF G16ANDG17THENK \\
\hline
\end{tabular}

Tabel 2 Data Aturan

1. Keterangan kode kerusakan :

$\mathrm{K} 1:$ Acu

$\mathrm{K} 2$ : Busi

K3 : Celah Klep 


\section{Analisis Perancangan Sistem}

1. Dią

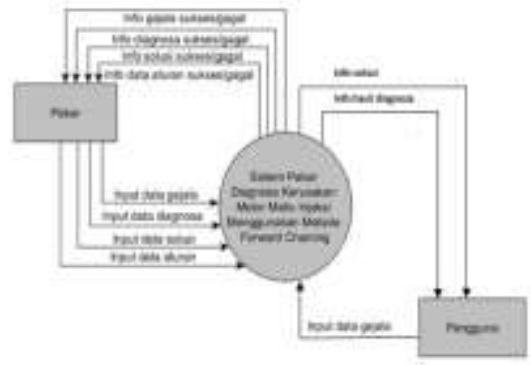

Gambar 2. Diagram Konteks

\section{Data Flow Diagram}

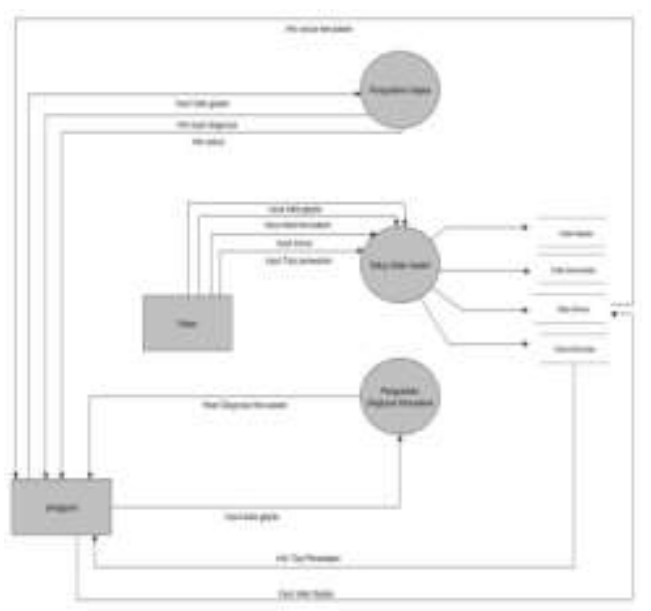

Gambar 3. Data Flow Diagram Level 1

Data Flow Diagram (DFD) level 1 dibuat untuk menggambarkan dari mana asal data dan kemana tujuan data yang keluar dari sistem, dimana data disimpan, proses apa yang dilakukan oleh sistem, sehingga dapat mempermudah dalam pembuatan sistem pakar diagnosa kerusakan sepeda motor matic injeksi ini.

Pada DFD level 1 sistem pakar ini terdiri dari :

1. Dua entitas eksternal yaitu pakar dan pengguna.

1. Tiga proses yaitu pengolahan gejala, setup data master, pengolahan diagnosa kerusakan.

2. Empat data penyimpanan yaitu data gejala, data kerusakan, data solusi, dan data informasi.

3. Proses pengolahan data gejala dilakukan oleh pakar untuk mengolah keluar masuk sistem.

4. pada data gejala disimpan ke tabel gejala, data kerusakan di simpan ke table kerusakan, data solusi disimpan ke table solusi dan data informasi disimpan ke table informasi.

5. Proses diagnosa dilakukan oleh pengguna dengan memasukkan data gejala kemudian disimpan ke tabel hasil diagnosa.

\section{Hasil Penelitian dan Pembahasan}

\section{A. Implementasi dan Pengujian}

Implementasi dan pengujian sistem ini dilakukan agar dapat mengetahui apakah sistem yang telah diimplementasikan dapat sesuai dengan tujuan sistem diagnosa kerusakan sepeda motor matic injeksi meggunakan metode forward chaining.

1. Implementasi Desin Interface

Implementasi desain interface merupakan pemaparan mengenai tampilan aplikasi dan kegunaan fungsi dari setiap activity yang ada. Untuk memperluas bentuk dari implementasi antarmuka, berikut pemaparan dan fungsi dari setiap tampilan yang telah dibuat, berikut ini tampilan Implementasi Desain Interface pada sistem pakar diagnosa kerusakan sepeda motor matic injeksi dengan menggunakan metode forward chaining berbasis mobile.

\section{Activity Halaman Utama}

Halaman ini merupakan tampilan awal sistem, sebagai halaman pembuka saat sistem dijalankan. Halaman ini berisi judul sistem, activity menu, profil dan keluar. Adapun tampilan utamadapat dilihat pada gambar 4 :

\section{Denas $\gg$ HOME \&}

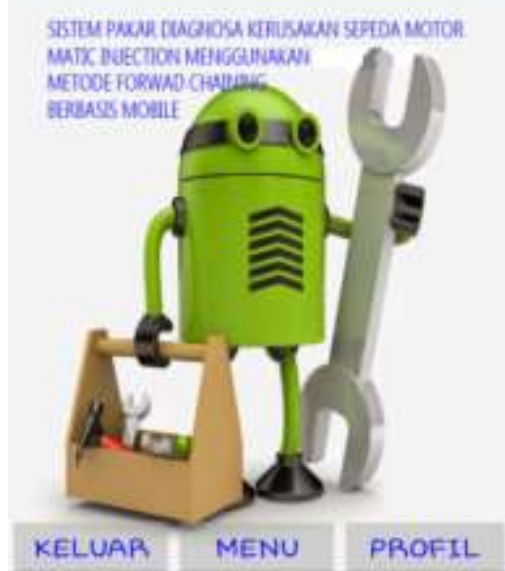

\section{Gambar 4 Activity Halaman Utama}

3. Activity Halaman Menu

Activity halaman menu ini berisi activity home, data, diagnosa, hasil diagnosa dan tips perawatan. Yang dapat dipilih oleh seorang pengguna atau user. Adapun tampilan activity menudapat dilihat pada gambar 5 :

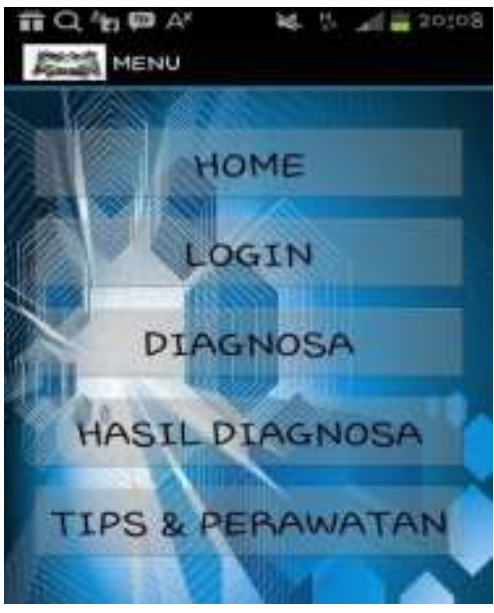

Gambar 5. Activity Halaman Menu 
4. Activity Halaman Data

Activity halaman data ini berisi data jenis kerusakan, data gejala dan data aturan. Adapun tampilan activity halaman data dapat dilihat pada gambar 6 :

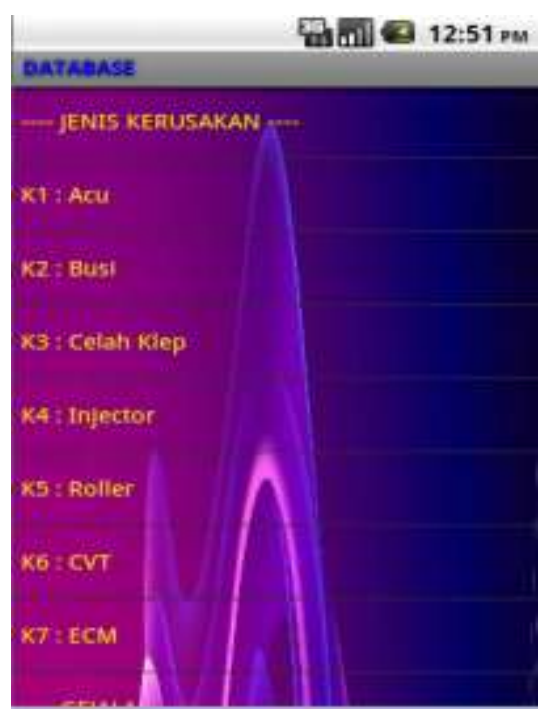

Gambar 6 Activity Halaman Data

\section{Activity Halaman Diagnosa}

Activity halaman diagnosa ini berisi gejalagejala kerusakan motor matic injeksi. Adapun tampilan activity halaman diagnosa dapat dilihat pada gambar 7 :

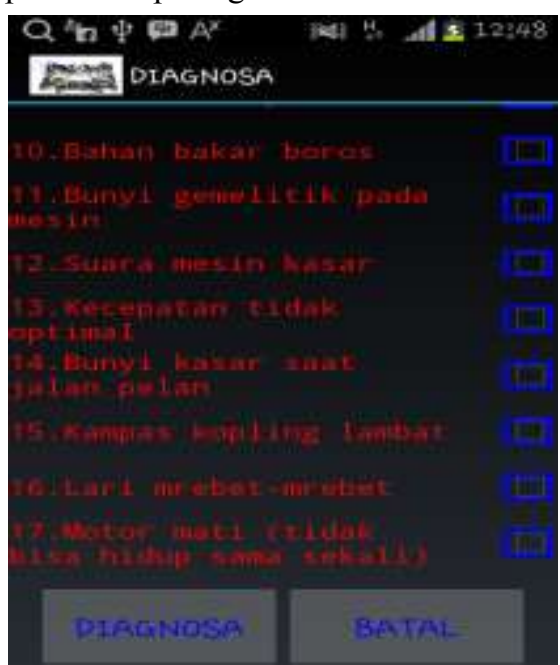

Gambar 7 Activity Halaman Diagnosa

6. Activity Halaman Hasil Diagnosa

Activity halaman hasil diagnosa ini berisi hasil diagnosa kerusakan/nama kerusakan motor matic yang muncul setelah memilih gejala-gejala kerusakan. Adapun tampilan activity halaman hasil diagnosa dapat dilihat pada gambar 8 :

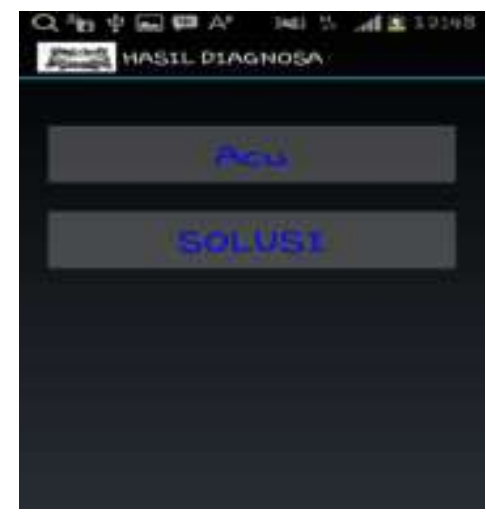

\section{Gambar 8 Activity Halaman Hasil Diagnosa}

\section{Activity Halaman Solusi}

Activity halaman solusi ini menjelaskan tentang solusi dari jenis kerusakan motor matic. Adapun tampilan activity halaman hasil diagnosa dapat dilihat pada gambar 9 :

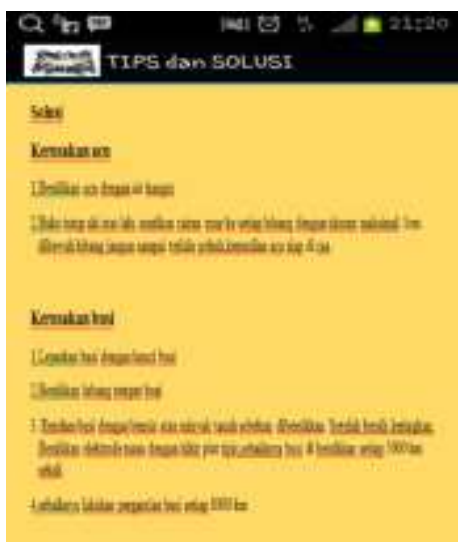

\section{Gambar 9 Activity Halaman Hasil Diagnosa dan Solusi}

\section{KESIMPULAN DAN SARAN}

\section{A. Kesimpulan}

Berdasarkan permasalahan yang dibangun pada aplikasi sistem pakar untuk diagnosa kerusakan dan perawatan pada motor matic injeksi berbasis android, maka dapat diambil beberapa kesimpulan adalah sebagai berikut :

1. Aplikasi yang dibangun ini membantu para pengguna motor matic injeksi untukmengetahui kerusakan motor matic injeksi berdasarkan gejala - gejala yang ada.

2. Berdasarkan dari hasil kuisioner aplikasi ini menggunakan metode forward chaining di dapat kan kesimpulan yang sesuai dari pengguna motor matic injeksi untuk mengetahui kerusakan motornya.

\section{B. Saran}

Saran yang dapat diberikan untuk pengembangan sistem pakar diagnosa kerusakan sepeda motor matic injeksi menggunakan metode Forward chaining ini agar menjadi lebih baik antara lain : 
1. Penelitian lanjutan dapat dikembangkan untuk diagnosa kerusakan sepeda motor matic non injeksi, sepeda motor injeksi non matic, dan sepeda motor non matic non injeksi.

2. Penelitian lanjutan dapat dikembangkan untuk diagnosa kerusakan sepeda motor matic injeksi ke platform yang lain, seperti : website, java atau ios.

3. Data yang diolah dapat dikembangkan dengan data - data penyebabnya

\section{Daftar Pustaka}

[1] Ardiansyah, F. 2011. "Pengenalan Dasar Android Programming". Biraynara. Jakarta.

[2] Arhami, M.2005. "Ciri ciri Sistem Pakar". Andi offset .Yogyakarta.

[3] Ferdianto. I, 2009. "Sistem Pakar [4] Moch. Solikin, 2005. Sistem Injeksi Bahan Bakar Motor Bensin (EFI System). Gava media.Yogyakarta: Kampong Ilmu

[4] Metode Forward Chaining"[online]. Tersedia: http: Sistem Pakar M.FC Indra Ferdianto's WebLoG. Htm [9Maret2017] 